\title{
Morphology control in precision polyolefins
}

\author{
Michael D. Schulz • Nicolas F. Sauty • \\ Kenneth B. Wagener
}

Received: 18 October 2013/Accepted: 7 November 2013/Published online: 7 December 2013

(c) The Author(s) 2013. This article is published with open access at Springerlink.com

\begin{abstract}
Herein, we review the major advances in controlling polyethylene morphology through precise control of branch frequency and identity. This control is made possible by the acyclic diene metathesis reaction.
\end{abstract}

Keywords ADMET · Olefin metathesis · Precision polyolefins · Polyethylene

\section{Introduction}

Polymer chemistry has changed the world. From the polyamides of Wallace Carothers to synthetic rubbers to the plastics that are ubiquitous in modern life, polymer science has provided the world with materials that have made modern life more convenient, affordable, and advanced. Despite being a relatively young field (less than a hundred years ago Hermann Staudinger was chided for even believing that macromolecules existed [1]), polymer science has built a considerable body of knowledge regarding structure-property relations. This knowledge begins with a thorough understanding of the primary structure of the polymer, i.e., the polymer repeat unit. Increasing levels of understanding can be built on this foundation (Fig. 1). How a single polymer chain organizes itself gives rise to the secondary structure. Multiple chains interact to give a tertiary structure. Finally, there is the morphological structure, and it is this structure that

M. D. Schulz · N. F. Sauty · K. B. Wagener $(\bowtie)$

The George and Josephine Butler Polymer Research Laboratory,

Department of Chemistry and Center for Macromolecular

Science and Engineering, University of Florida, Gainesville, FL 32611-7200, USA

e-mail: wagener@chem.ufl.edu ultimately determines the material properties. Understanding, however, begins at the most fundamental levelthe repeat unit.

\section{ADMET polymerization}

We study olefin metathesis. Our understanding of this reaction provides the foundation on which we have built the precision polyolefin paradigm. Our group has pioneered the field of acyclic diene metathesis (ADMET) polymerization [2], in which a diene is condensed via metathesis to give an unsaturated polymer and a small molecule condensate (usually ethylene) (Fig. 2).

The development of well-defined catalysts was key. Initial work using $\mathrm{WCl}_{6}$ and a Lewis acid to promote olefin metathesis produced a mixture of products-low molecular weight oligomers, insoluble material, and gaseous ethylene. It was discovered that to form high molecular weight polymer, there could be no side reactions (particularly vinyl addition) competing with the olefin metathesis. Serendipitously, this realization coincided with the report of the first Schrock catalysts, enabling the rapid development of the burgeoning field of metathesis polymerization.

ADMET polymerization is a reversible reaction. Consequently, to achieve high molecular weights the reaction equilibrium must be driven toward polymer formation by the removal of the small molecule condensate. Thus, high vacuum conditions are almost always required. ADMET polymerization is concentration dependent, with bulk conditions often being the optimum. Like other condensation polymerizations, ADMET polymerization results in relatively broad molecular weight distributions (PDI $\approx 2.0$ ). Unlike ring-opening metathesis polymerization (ROMP), the metathesis chain polymerization, ADMET produces

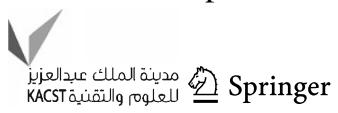


Fig. 1 Structural hierarchy

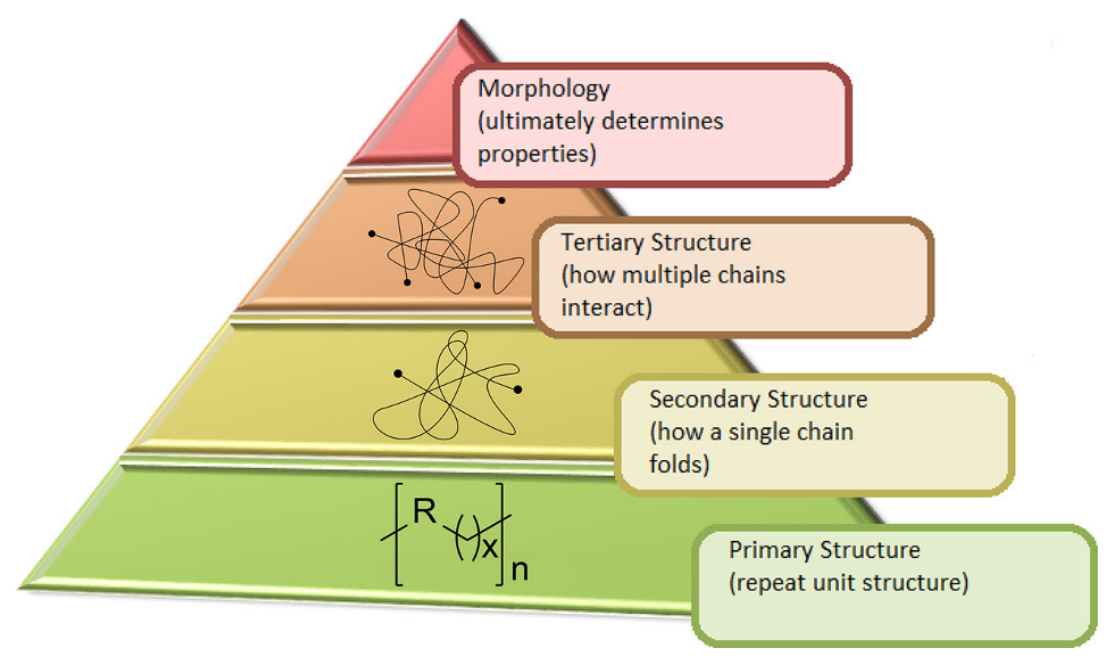

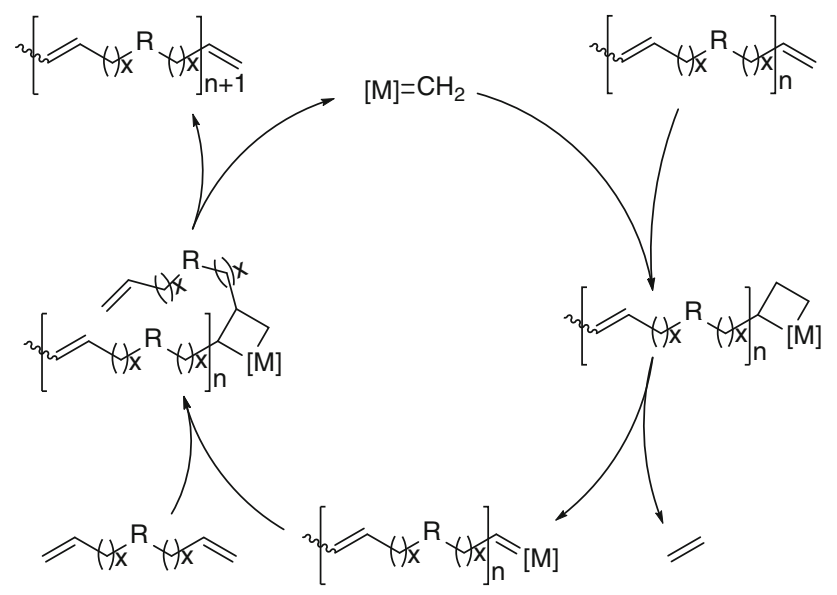

Fig. 2 ADMET polymerization mechanism

polymers that are most often semicrystalline, with molecular weights typical of other polycondensations. As ring-strain in the monomer is not required, a wide variety of diene monomers is possible. ADMET has been used to produce polymers containing simple hydrocarbons [3, 4], aromatic amines [5], branched acids [6,7], ethers [8, 9], silanes [10], acetals [11], esters [12-15], aromatic moieties [16-20], thioethers [21], and ketones [14, 22], to name a few.

\section{What are "precision polyolefins"?}

Polyolefins are usually made by chain polymerization. In the case of polyethylene, the polymerization conditions of ethylene can be varied to produce materials with a wide variety of properties (HDPE, LDPE, LLDPE, just to name a few). These properties are almost always related to branchingbranch frequency and branch identity. While the amount of branching can be grossly controlled and characterized, the primary structure of the polymer is random. This makes is it impossible to systematically study the structure-property relationships at the most basic level. ADMET chemistry has solved this problem. By building symmetry into the monomer itself, we are able to precisely control the branch identity and frequency in ADMET polyethylene. Because of this precise control, we call the materials produced by this method "Precision Polyolefins" (Fig. 3).

\section{Effect of branch identity}

Among the first polymers to be synthesized and studied using ADMET was a precision analog of an ethylene/ propylene copolymer, which may be described as polyethylene with a methyl branch on every 21 st carbon. This material was then compared to a polymer where the methyl group was on average on every 21 st carbon. The difference between the thermal properties of these two materials is striking. The precise polymer showed a sharp melt transition, whereas the random analog had a very broad transition (Fig. 4). It is clear that the precise placement of branches affects material properties. But are these methyl branches included in the crystal lattice of the polymer?

ADMET polyethylene is orthorhombic. When methyl groups are incorporated on every 21 st carbon, they are indeed included in the crystal lattice; however, there is a change to a triclinic lattice with a hexagonal subcell of methylene groups. Using transmission electron microscopy (TEM), we determined that the lamella thickness in this material is between 10 and $20 \mathrm{~nm}$ [24].

We subsequently broadened our study to include a wide variety of alkyl groups, to determine the effects of branch identity (Table 1). This effort was aided by the development of a two-step monomer synthesis by Giovanni Rojas [25]. We synthesized polymers with alkyl branches of various sizes ranging from a methyl group to an adamantyl group. Despite the diversity of branch identities, these polymers could be simply divided into two groups-those 
in which the branch is included in the unit cell, and those in which the branch is excluded from the unit cell. When the branch is included in the unit cell, the crystal lattice is triclinic. When the branch is excluded, the crystal lattice is orthorhombic. For the series of polymers with a branch on every 21 st carbon, three branch types were included in the unit cell: methyl, gem-dimethyl, and ethyl [26]. The

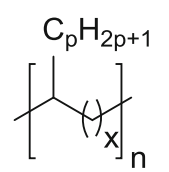<smiles>CC(C)(C)C1CCCCC1C(=O)O</smiles><smiles>CC(C)CC(C(C)C)C(C)(C)C</smiles><smiles>[Y]C1CCC(C(C)(C)C)C1S(=O)(=O)O</smiles>

Fig. 3 Selected examples of precision polymers

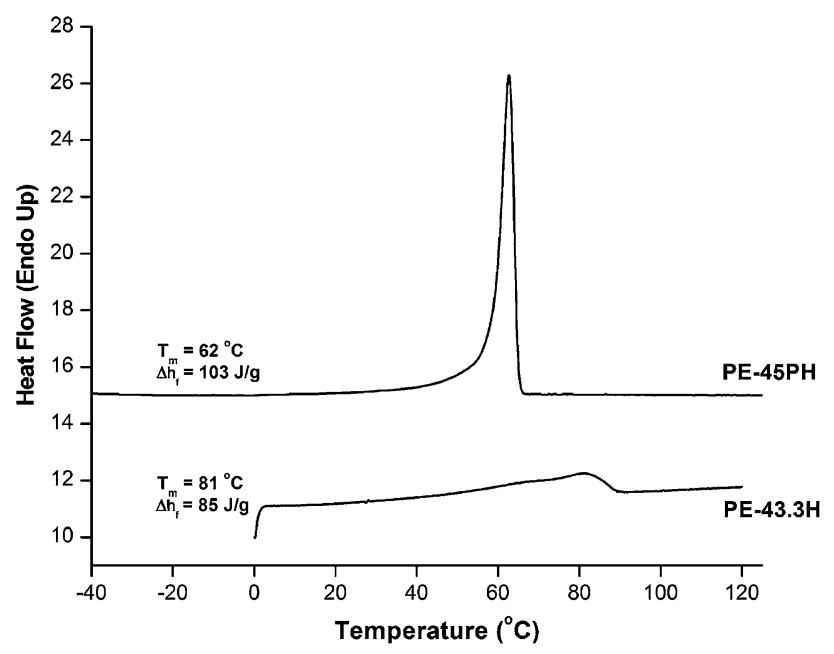

Fig. 4 ADMET methyl-branched polyethylene: precision (top) versus random (bottom) [23] polymers with branches included in the unit cell display decreasing melting temperatures with increasing branch size. The trend continues as the series is extended from the ethyl to the propyl branch; however, even as the branch size continues to increase, the polymers with branches excluded from the unit cell all display very similar melting temperatures.

The crystalline structures of ADMET polyethylene with ethyl or $n$-hexyl branches were studied using TEM [27]. These measurements showed that the ethyl-branched sample displayed straight lamellar crystals with an average thickness of $55 \AA$. This length corresponds to twice the ethylene sequence length between branches, indicating that one lamellar stem includes three ethyl branches, one of which is within the lamella. Similar measurements were performed on ADMET polyethylene with $n$-hexyl branches on every 21 st carbon. This material displayed a narrow lamella thickness distribution, with lamellae averaging 25-26 $\AA$ in thickness. This length indicates that one lamella stem comprises a single ethylene sequence between two branches, further supporting the conclusion that the larger hexyl branch is entirely excluded from the crystalline phase.

\section{Effect of branch spacing}

We know that methyl branches are included in the polymer crystal lattice, but what effect does the branch frequency have on polymer morphology? To answer this question, a series of precise methyl-branched polymers was synthesized (Table from slide 30), ranging from having a methyl branch on every fifth carbon, to having a branch on every
Table 1 Thermal and crystallographic data of alkylbranched precision polyethylene $[26,28,29]$

\begin{tabular}{|c|c|c|c|c|c|c|}
\hline \multicolumn{3}{|l|}{ Alkyl branch on every 21 st carbon } & \multirow[t]{2}{*}{ Alkyl branch } & \multicolumn{3}{|c|}{ Alkyl branch on every 39th carbon } \\
\hline $\begin{array}{l}\text { Branch inclusion } \\
\text { in unit cell }\end{array}$ & $T_{\mathrm{m}}\left({ }^{\circ} \mathrm{C}\right)$ & $\Delta h_{\mathrm{m}}(\mathrm{J} / \mathrm{g})$ & & $T_{\mathrm{m}}\left({ }^{\circ} \mathrm{C}\right)$ & $\Delta h_{\mathrm{m}}(\mathrm{J} / \mathrm{g})$ & $\begin{array}{l}\text { Branch inclusion } \\
\text { in unit cell }\end{array}$ \\
\hline \multirow[t]{4}{*}{ Included triclinic system } & 134 & 204 & No branch & 134 & 204 & Included \\
\hline & 63 & 104 & Methyl & 92 & 137 & \\
\hline & 45 & 61 & $\begin{array}{l}\text { gem- } \\
\text { Dimethyl }\end{array}$ & - & - & Excluded \\
\hline & 24 & 65 & Ethyl & 76 & 93 & \\
\hline \multirow[t]{9}{*}{ Excluded orthorhombic system } & 12 & 60 & Propyl & 78 & 71 & \\
\hline & 12 & 57 & Butyl & 76 & 128 & \\
\hline & 14 & 58 & Pentyl & 74 & 74 & \\
\hline & 12 & 49 & Hexyl & 73 & 73 & \\
\hline & - & - & Decyl & 71 & 76 & \\
\hline & - & - & Pentadecyl & 70 & 83 & \\
\hline & 11 & 37 & iso-Propyl & 77 & 74 & \\
\hline & 13 & 50 & tert-Butyl & - & - & \\
\hline & 9 & 43 & sec-Butyl & - & - & \\
\hline
\end{tabular}


21st carbon, and ultimately having no branches (linear ADMET polyethylene). These precise ethylene-co-propylene copolymers displayed a melting point range of almost $200^{\circ} \mathrm{C}$. When a methyl group was incorporated on every fifth carbon, the polymer was completely amorphous. As the distance between the branches increased, the melting temperature also increased. This indicates that as the frequency of branch defects decreases, the crystallinity of the polymer is increased.

A series of alkyl-branched polymers with precise branches on every 39th carbon were also synthesized (Table 1) $[28,29]$. Unlike the previous alkyl-branched series, with branches on every 21 st carbon, the ethyl branch was excluded from the unit cell of these polymers. This demonstrates the importance of branch frequency. As the distance between branches increases, the crystalline region becomes more likely to exclude branch defects. Again, each polymer with branches excluded from the unit cell displayed similar melting temperatures (around $74{ }^{\circ} \mathrm{C}$ ). The distance between precise branch points was even further extended to 74 methylene units between butyl branches [30]. From this work, we can conclude that melting point is determined by branch-to-branch distance-up to 75 carbons (Fig. 5) [27]. We believe chains fold to form lamellae devoid of large defects. Thus, the larger alkyl groups are excluded from the crystal lattice. However, the distance between branch points must be large enough to allow crystallization to occur. When there are no branches, orthorhombic crystals form; when there are small, precisely placed branches, they are included in the crystal, resulting in a triclinic unit cell; when there are large, precisely placed branches, they are excluded from the crystal, and the polymer reverts to an orthorhombic crystal.

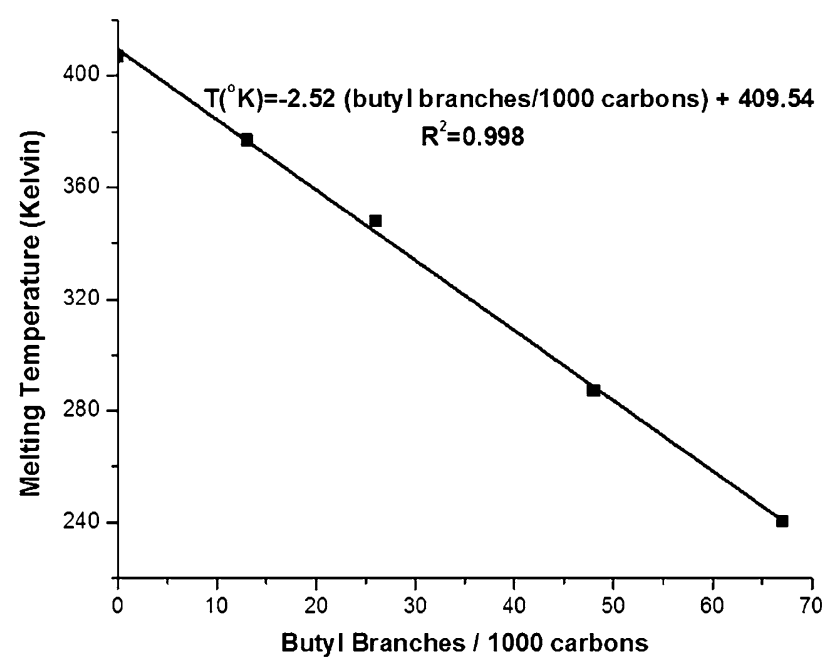

Fig. 5 Linear relationship between melting temperature and branch frequency in precision butyl-branched polyethylene [30]
We know that large precision branches are excluded from the crystalline region of the polymer, but is there some special "ordering" of these branches in the amorphous region? Such interactions in the amorphous region were first observed at Sumitomo Chemical Company [31]. When ADMET polyethylene with either an ethyl branch or an $n$-hexyl was isothermally crystallized at the crystallization temperature, the formation of a transient-ordered mesophase and subsequent crystallization through packing optimization was observed. This raises the question, if alkyl branches interact in the amorphous region of the polymer, how would strongly interacting groups affect the polymer morphology?

\section{Precision Acid and ionomer functional group branches}

To investigate the effect of strongly interacting groups precisely placed on a polyethylene backbone, a series of polymers were designed and synthesized with pendant carboxylic acid groups. The synthesis of these polymers was straight forward, and involved the polymerization of a protected carboxylic acid (Fig. 6). In this case, hydrogenation not only reduced the double bonds in the polymer backbone, but also removed the protecting group, yielding the final polymer. Carboxylic acid branches were included on ever 9th, 15th, and 21 st carbon. In the case of the polymer with carboxylic acid groups on every 21 st carbon, the acid groups were excluded from the polyethylene-like orthorhombic unit cell. When the acid branches were more frequent, the polymers were amorphous due to increased steric congestion along the polymer backbone (Fig. 7) [6] Analogous polymers were created using ROMP, which had the same concentration of acid groups along the polymer backbone, but without precise spacing.

From FTIR evidence, we know the carboxylic acid groups on the polymer dimerize. Interestingly, these acid-acid correlations persist above the melt [22]. The correlations between acid dimers in the amorphous matrix result in an $\mathrm{X}$-ray scattering peak, which is not observed in the random ROMP analogs, due to the fact that the dimer positions are uncorrelated. Analysis of the X-ray scattering pattern of a sample made from the ADMET ethylene/acrylic acid copolymer indicated a layered structure, where each lamellae is approximately $2.6-4.2 \mathrm{~nm}$ thick and contains $2-3$ acid-

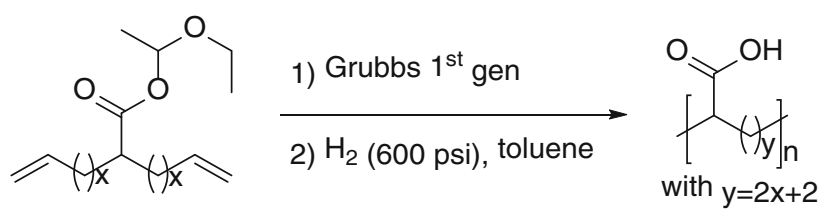

Fig. 6 Precision carboxylic acid-branched polyethylene [6] 


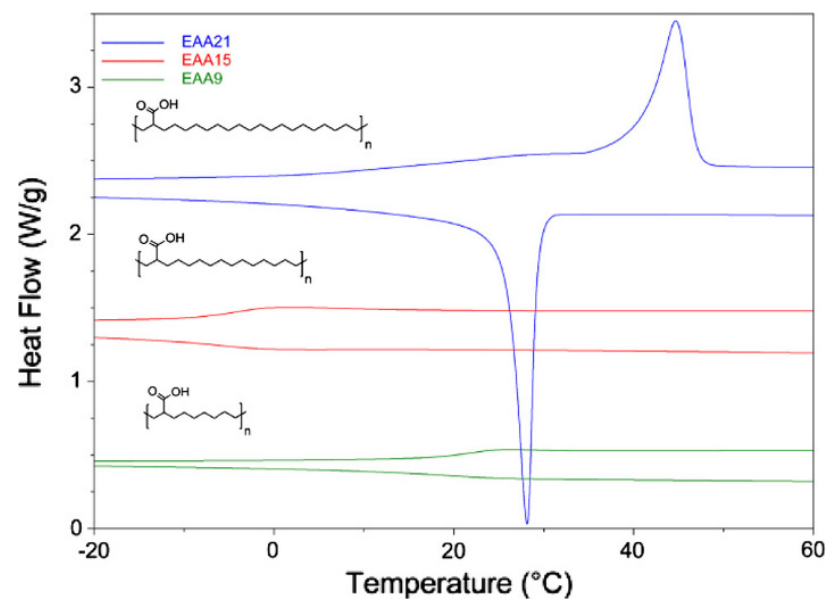

Fig. 7 Differential scanning calorimetry analysis of carboxylic acidfunctionalized precision polyethylene [6]

rich layers. This layered morphology was absent from the ROMP analogs, in which the random placement of the acid groups accommodates the H-bonding acid dimerization without producing periodic acid-rich layers.

These precise carboxylic acid polymers were subsequently transformed to ionomers. An ionomer is a polymeric material that contains ionic units. Typically, such materials exhibit ionic clustering due to polar functional groups trapped within a nonpolar matrix. From the precise and random series of ethylene/acrylic acid copolymers, a new series of zinc-neutralized ionomers were created and studied. The ionic aggregates in an amorphous, precise ionomer with $22 \mathrm{~mol} \%$ acid and $66 \%$ neutralization adopt a cubic lattice. This was a remarkable observation, given that it is the first report of ionic aggregate self-assembly onto a lattice in an ionomer with an all-carbon backbone [32].

Because the primary structure of these precision ionomers is known exactly, they are particularly useful for comparison between theoretical simulation and experimental results. At Sandia National Laboratories, a set of coarse-grained molecular dynamics simulations of ionomer melts with varying polymer architectures was performed. These results were then compared to experiments to understand ionic aggregation at the molecular level [33]. Our materials are ideal for clear comparisons with simulations because they have a much stronger ionomer scattering peak than randomly spaced analogs, and because of their highly ordered morphology. In this work, the effect of varying the spacing between charges and the effect of randomness in the spacing was studied. Simulations of both precise and random $\mathrm{Na}^{+}$neutralized poly(ethylene-co-acrylic acid) ionomers were compared with X-ray scattering data. In both the simulation and experimental data it was found that increasing the spacing between ions along the chain moves the peak to a lower wave vector for precise materials. Additionally, moving from precise to pseudorandom materials broadens the ionomer peak and moves it to a lower wave vector. This is also seen in simulation when moving from periodic to random block models.

The characterization of our precise carboxylic acid ADMET polymers established that strongly interacting pendant groups have a profound effect on polymer morphology. However, a carboxylic acid has only one acidic proton. What if each pendant group had even greater H-bonding capabilities? To answer this question, we synthesized a series of precision polymers with pendant phosphonic acid groups [7, 34]. In this series, both frequency of acid appearance along the polymer backbone and the architectures associated with each position (single, germinal, and benzyl) were varied. The variation in the primary structure had a direct effect on thermal behavior, particularly crystallization behavior. A logical next step would be the synthesis of a sulfonic acidbranched polymer. This polymer, with triprotic-interacting branches, would potentially have even stronger interactions between the acid groups. Additionally, data generated through studying such a polymer would have implications for fuel cell membranes and proton conduction membranes, which utilize sulfonic acid groups. Synthesis of this material is ongoing in our lab.

\section{Conclusion}

Using ADMET polymerization, we have expanded our understanding of fundamental structure-property relations. Our ability to set the primary structure has allowed us to systematically study morphology with a greater degree of control. The key is precision. The precise placement of specific branches at precise increments along the polymer backbone leads to significant and quantifiable effects in the polymer morphology. Our understanding of the connection between variations in the primary structure and variations in morphology would not be possible, however, without first knowing the repeat unit of the polymer. Thus, understanding is built on the fundamental chemistry involved: Understanding the metathesis reaction allows the design of the primary structure, which allows control over the higher levels of organization, leading ultimately to control over morphology.

Open Access This article is distributed under the terms of the Creative Commons Attribution License which permits any use, distribution, and reproduction in any medium, provided the original author(s) and the source are credited.

\section{References}

1. Staudinger H (1961) Arbeitserinnerungen. Alfred Huthig, Heidelberg 
2. Atallah P, Wagener KB, Schulz MD (2013) ADMET: the future revealed. Macromolecules 46:4735-4741

3. Berda E, Baughman T, Wagener KB (2006) Precision branching in ethylene copolymers: synthesis and thermal behavior. J Polym Sci Part A: Polym Chem 44:4981-4989

4. Rojas G, Berda EB, Wagener KB (2008) Precision polyolefin structure: modeling polyethylene containing alkyl branches. Polymer 49:2985-2995

5. Portmess JD, Wagener KB (1996) Acyclic diene metathesis (ADMET) polymerization: the synthesis of unsaturated polyamines. J Polym Sci Part A: Polym Chem 34:1353-1357

6. Baughman TW, Chan CD, Winey KI, Wagener KB (2007) Synthesis and morphology of well-defined poly(ethylene-coacrylic acid) copolymers. Macromolecules 40:6564-6571

7. Opper KL, Fassbender B, Brunklaus G, Spiess HW, Wagener KB (2009) Polyethylene functionalized with precisely spaced phosphonic acid groups. Macromolecules 42:4407-4409

8. Wagener KB, Brzezinska K (1991) Acyclic diene metathesis (ADMET) polymerization. Synthesis of unsaturated polyethers. Macromolecules 24:5273-5277

9. Wagener KB, Brzezinska K, Bauch CG (1992) Acyclic diene metathesis (ADMET) polymerization. The preparation of symunsaturated polyethers by the use of $\mathrm{Mo}(\mathrm{CH}-t-\mathrm{Bu})\left(\mathrm{N}-2,6-\mathrm{C}_{6} \mathrm{H}_{3}-i\right.$ $\left.\mathrm{Pr}_{2}\right)\left[\mathrm{OCCH}_{3}\left(\mathrm{CF}_{3}\right)_{2}\right]_{2}$ catalyst. Makromol Chem Rapid Commun 13:109-115

10. Wagener KB, Smith DW Jr (1991) Acyclic diene metathesis polymerization. Synthesis and characterization of unsaturated poly[carbo(dimethyl)silanes]. Macromolecules 24:6073-6078

11. Wolfe PS, Wagener KB (1996) An ADMET route to unsaturated polyacetals. Macromol Rapid Commun 19:305-308

12. Patton JT, Boncella JM, Wagener KB (1992) Acyclic diene metathesis (ADMET) polymerization. The synthesis of unsaturated polyesters. Macromolecules 25:3862-3867

13. Bauch CG, Wagener KB, Boncella JM (1991) Acyclic diene metathesis (ADMET) polymerization. Synthesis of an unsaturated polyester. Makromol Chem Rapid Commun 12:413-417

14. Watson MD, Wagener KB (2000) Ethylene/vinyl acetate copolymers via acyclic diene metathesis polymerization. Examining the effect of "long" precise ethylene run lengths. Macromolecules 33:5411-5417

15. Tindall D, Wagener KB (2004) Acyclic diene metathesis (ADMET) segmented copolymers. Macromolecules 37:3328-3336

16. Fox HH, Schrock RR, O'Dell R (1994) Coupling of terminal olefins by molybdenum (VI) imido alkylidene complexes. Organometallics 13:635-639

17. Thorn-Csányi E, Pflug KP (1993) Copolymers of 1,5-cyclooctadiene and [2.2]paracyclophane-1,9-diene: metathetic preparation and structure analysis. Makromol Chem Rapid Commun 13:619-624

18. Thorn-Csányi E, Pflug KP (1994) Synthesis of oligo- and poly(1,4-phenylenevinylene) by metathetic polycondensation of 1,4-divinylbenzene. J Mol Catal 90:29-37

19. Qin Y, Hillmyer MA (2009) Poly(3-hexyl-2,5-thienylene vinylene) by ADMET polymerization of a dipropenyl monomer. Macromolecules 42:6429-6432
20. Delgado PA, Liu DY, Kean A, Wagener KB (2011) Synthesis of poly(3-dodecyl-2,5-thienylene vinylene) by solid-state metathesis polycondensation. Macromolecules 44:9529-9532

21. O'Gara JK, Portmess JD, Wagener KB (1993) Acyclic diene metathesis (ADMET) polymerization. Synthesis of unsaturated polythioethers. Macromolecules 26:2837-2841

22. Forbes MDE, Patton JT, Myers TL, Maynard HD, Smith DW Jr, Schultz GR, Wagener KB (1992) Solvent-free cyclization of linear dienes using olefin metathesis and the Thorpe-Ingold effect. J Am Chem Soc. 114:10978-10980

23. Sworen JC, Smith JA, Wagener KB, Baugh LS, Rucker SP (2003) Modeling random methyl branching in ethylene/propylene copolymers using metathesis chemistry: synthesis and thermal behavior. J Am Chem Soc 125:2228-2240

24. Lieser G, Wegner G, Smith JA, Wagener KB (2004) Morphology and packing behavior of model ethylene/propylene copolymers with precise methyl branch placement. Colloid Polym Sci 282:773-781

25. Rojas G, Wagener KB (2008) Avoiding olefin isomerization during decyanation of alkylcyano $\alpha$, $\omega$-dienes: a deuterium labeling and structural study of mechanism. J Org Chem 73:4962-4970

26. Rojas G, Inci B, Wei Y, Wagener KB (2009) Precision polyethylene: changes in morphology as a function of alkyl branch size. J Am Chem Soc 131:17376-17386

27. Hosoda S, Nozue Y, Kawashima Y, Utsumi S, Nagamatsu T, Wagener KB, Berda E, Rojas G, Baughman T, Leonard J (2009) Perfectly controlled lamella thickness and thickness distribution: a morphological study on ADMET polyolefins. Macromol Symp 282:50-64

28. Zuluaga F, Inci B, Nozue Y, Hosoda S, Wagener KB (2009) Reducing branch frequency in precision polyethylene. Macromolecules 42:4953-4955

29. Inci B, Lieberwirth I, Steffen W, Mezger M, Graf R, Landfster K, Wagener KB (2012) Decreasing the alkyl branch frequency in precision polyethylene: effect of alkyl branch size on nanoscale morphology. Macromolecules 45:3367-3376

30. Inci B, Wagener KB (2011) Decreasing the alkyl branch frequency in precision polyethylene: pushing the limits towards longer run lengths. J Am Chem Soc 133:11872-11875

31. Nozue Y, Kawashima Y, Seno S, Nagamatsu T, Hosoda S, Berda EB, Rojas G, Baughman TW, Wagener KB (2011) Unusual crystallization behavior of polyethylene having precisely spaced branches. Macromolecules 44:4030-4034

32. Seitz ME, Chan CD, Opper KL, Baughman TW, Wagener KB, Winey KI (2010) Nanoscale morphology in precisely sequenced poly(ethylene-co-acrylic acid) zinc ionomers. J Am Chem Soc 132:8165-8174

33. Hall LM, Seitz ME, Winey KI, Opper KL, Wagener KB, Stevens MJ, Frischkenect AL (2012) Ionic aggregate structure in ionomer melts: effect of molecular architecture on aggregates and the ionomer peak. J Am Chem Soc 134:574-587

34. Opper KL, Markova D, Klapper M, Müllen K, Wagener KB (2010) Precision phosphonic acid functionalized polyolefin architectures. Macromolecules 43:3690-3698 